Check for updates

Cite this: RSC Adv., 2017, 7, 25450

Received 16th March 2017

Accepted 8th May 2017

DOI: 10.1039/c7ra03116e

rsc.li/rsc-advances

\title{
Ultrathin Janus nanodiscs $\uparrow$
}

\author{
Dan Xue, ${ }^{\text {ab }}$ Ximing Song $\mathbb{D}^{\mathrm{a}}$ and Fuxin Liang (D) *b
}

\begin{abstract}
Ultrathin Janus nanodiscs with single molecular scale thickness are fabricated by self-organized sol-gel process against a patchy magnetic microsphere. Functional groups onto the patch domains can induce a favourable absorption of an amine. The morphology of Janus nanodiscs is adjusted by controlling the patchy regions on the surface of paramagnetic $\mathrm{Fe}_{3} \mathrm{O}_{4} \mathrm{CSiO}_{2}$ core/shell microspheres. The as-used patchy $\mathrm{C}_{8}-\left(\mathrm{Fe}_{3} \mathrm{O}_{4}\left(\mathrm{aSiO}_{2}\right)-\mathrm{PhCHO}\right.$ microspheres serving as templates can be easily separated from the as-formed Janus nanodiscs and reused to fabricate other Janus nanodiscs. Functional compositions such as paramagnetic $\mathrm{Fe}_{3} \mathrm{O}_{4}$ nanoparticles and polymers with different wettability properties are introduced onto the different regions of Janus nanodiscs to achieve magnetic Janus nanodiscs. They are used as efficient solid surfactants to stabilize emulsion.
\end{abstract}

\section{Introduction}

Janus materials with two different compositions and properties distinctly compartmentalized onto the same surface of one object have gained growing academic and industrial interests. It is important to develop methods to tune their morphology, composition thus function spatial distribution. ${ }^{1}$ Concerning with wettability difference of the two compositions, amphiphilic Janus materials can serve as a solid surfactant to stabilize immiscible liquids. ${ }^{2}$ Among the representative shapes, such as 0-D (zero-dimensional) Janus spheres, ${ }^{3}$ 1-D Janus rods, ${ }^{4}$ 2-D Janus discs, ${ }^{5}$ and 3-D Janus cages, ${ }^{6}$ Janus discs are efficient solid surfactants for their anisotropic shapes. Serving as emulsion stabilizers, rotation of the Janus discs (or named sheets) with anisotropic shapes is restricted. So the orientation of Janus discs has definite direction, and the as-formed emulsion is very stable. ${ }^{7}$ So the as-stabilized emulsion is more stable than that upon using spherical Janus particles. But disc-like Janus materials are difficult to be obtained. Polymeric nano-sized Janus discs have been fabricated via self-assembly of block copolymers. ${ }^{8}$ But the narrow molecular weight is needed for the as-used block copolymers to self-assembly forming a layered structure. Recently, we have fabricated Janus nanosheets with molecular scale thickness by a surface sol-gel process of the selfassembled monolayer of an amphiphilic silane onto the template particles. ${ }^{9}$ For their ultrathin thickness, Janus nanosheets are flexible to tightly adhere onto the interface

${ }^{a}$ Liaoning Provincial Key Laboratory for Green Synthesis and Preparative Chemistry of Advanced Materials, Liaoning University, Shenyang 110036, China

${ }^{b}$ State Key Laboratory of Polymer Physics and Chemistry, Institute of Chemistry, Chinese Academy of Sciences, Beijing 100190, China. E-mail: liangfuxin@iccas.ac.cn $\dagger$ Electronic supplementary information (ESI) available: Fig. 1-9. See DOI: 10.1039/c7ra03116e with appropriate deformation. But in all these Janus discs, their shapes and sizes are difficult to be controlled because all of them are achieved by crushing process.

Herein, we report a novel approach towards Janus nanodiscs with single molecular scale thickness against a patchy $\mathrm{Fe}_{3}$ $\mathrm{O}_{4} @ \mathrm{SiO}_{2}$ core/shell microsphere (Scheme 1). The aldehyde groups in the patchy domains can induce a favourable absorption of 3-aminopropyltrimethoxysilane (APTMS) via a dynamic imine bond. After removal residual APTMS, a monolayer of APTMS forms onto the patchy domain. The pedant silane groups direct outwardly, which can form a molecular thick silica layer after a sol-gel process. Under acidic conditions, when the imide bond is broken, the Janus nanodiscs are released from the $\mathrm{Fe}_{3} \mathrm{O}_{4} @ \mathrm{SiO}_{2}$ microspheres. Further, paramagnetic $\mathrm{Fe}_{3} \mathrm{O}_{4}$ nanoparticles and polymers with different wettability properties are introduced onto the different sides of the ultrathin Janus nanodiscs to achieve functional ultrathin Janus nanodiscs. They could be served as efficient solid surfactants to stabilize emulsion.

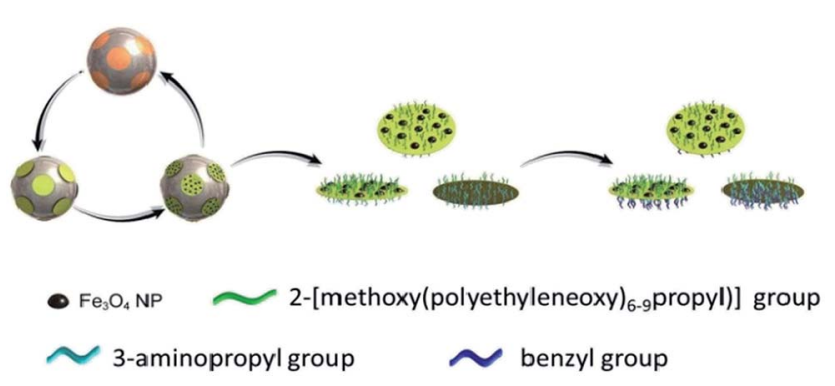

Scheme 1 Synthesis of ultrathin Janus nanodiscs. The patchy magnetic $\mathrm{Fe}_{3} \mathrm{O}_{4} \mathrm{QSiO}_{2}$ core/shell microspheres as template can be recycled and the Janus nanodiscs are modified with $\mathrm{Fe}_{3} \mathrm{O}_{4} \mathrm{NPs}$ and hydrophilic PEO group on the one side and hydrophobic benzyl group on the other side. 


\section{Experimental}

\section{Materials}

Iron(III) chloride hexahydrate $\left(\mathrm{FeCl}_{3} \cdot 6 \mathrm{H}_{2} \mathrm{O}\right)$, iron chloride tetrahydrate $\left(\mathrm{FeCl}_{2} \cdot 4 \mathrm{H}_{2} \mathrm{O}\right)$, ethylene glycol (EG), sodium acetate trihydrate (NaAC), sodium citrate, hydrochloride acid ( $\mathrm{HCl})$, ammonium hydroxide (25 wt\%), tetraethyl orthosilicate (TEOS), sliver nitrate $\left(\mathrm{AgNO}_{3}\right)$, nitric acid $\left(\mathrm{HNO}_{3}\right)$, dimethyl sulphoxide (DMSO), potassium iodide (KI), sodium bicarbonate $\left(\mathrm{NaHCO}_{3}\right)$, benzaldehyde, paraffin $\left(52-54{ }^{\circ} \mathrm{C}\right)$, tetrahydrofuran (THF), $N$-heptane, sodium borohydride $\left(\mathrm{NaBH}_{4}\right)$ and cyclohexane were purchased from Sinopharm Chemical Reagent. $N$-Butylamine was purchased from ACROS. 4-(chloromethyl)phenyltrimethoxysilane ( $\left.\mathrm{PhCH}_{2} \mathrm{Cl}-\mathrm{TMS}\right)$ were purchased from Alfa Aesar. $N$-Octyltrimethoxysilane $\left(\mathrm{C}_{8}-\right.$ TMS), 3-aminopropyltrimethoxysilane (APTMS), fluorescein isothiocyanate isomer1 (FITC) and coumarine-6 were purchased from J\&K. 2-[Methoxy(polyethyleneoxy) ${ }_{6-9}$ propyl]trimethoxysilane (PEOTMS) was purchase from Fluorochem.

Preparation of $\mathrm{Fe}_{3} \mathrm{O}_{4}$ microspheres. $3.76 \mathrm{~g}$ of $\mathrm{FeCl}_{3} \cdot 6 \mathrm{H}_{2} \mathrm{O}$ and $10.03 \mathrm{~g}$ of NaAC were dispersed in $139 \mathrm{ml}$ of EG under ultrasonic. Shifted them to hydrothermal reactor and sealed, heated to $200{ }^{\circ} \mathrm{C}$ for $8 \mathrm{~h}$. Cooled it to room temperature and got precipitated black magnetic microspheres which were $\mathrm{Fe}_{3} \mathrm{O}_{4}$ microspheres.

Preparation of $\mathrm{Fe}_{3} \mathrm{O}_{4} @ \mathrm{SiO}_{2}$ core/shell microspheres. $0.1 \mathrm{~g}$ of $\mathrm{Fe}_{3} \mathrm{O}_{4}$ microspheres were dispersed in $20 \mathrm{ml}$ of sodium citrate solution ( $10 \mathrm{wt} \%$ ) for $0.5 \mathrm{~h}$ after being etched by $20 \mathrm{ml}$ of $\mathrm{HCl}$ (2 $\mathrm{M})$ solution for $2 \mathrm{~min}$ under ultrasonic. And then dispersed the $\mathrm{Fe}_{3} \mathrm{O}_{4}$ microspheres in the solution containing $54 \mathrm{ml}$ of ethanol, $9 \mathrm{ml}$ of water and $0.9 \mathrm{ml}$ of ammonium hydroxide (25 wt\%) under ultrasonic for $1 \mathrm{~h}$. Added $0.3 \mathrm{ml}$ of tetraethylorthosilicate (TEOS) and stirred them at room temperature for $10 \mathrm{~h}$.

Preparation of patchy templated microspheres. Firstly, $150 \mathrm{mg}$ of $\mathrm{Fe}_{3} \mathrm{O}_{4} @ \mathrm{SiO}_{2}$ core/shell microspheres were dispersed in $100 \mathrm{ml}$ of ethanol under ultrasonic. $120 \mathrm{mg}$ of $\mathrm{AgNO}_{3}$ and $70 \mathrm{ml}$ of $n$-butylamine were added into the mixture and stirred them for $50 \mathrm{~min}$ at $50{ }^{\circ} \mathrm{C}$. Patchy $\left(\mathrm{Fe}_{3} \mathrm{O}_{4} @ \mathrm{SiO}_{2}\right)-\mathrm{Ag}$ microspheres were obtained. Secondly, $10 \mathrm{mg}$ of patchy $\left(\mathrm{Fe}_{3} \mathrm{O}_{4} @\right.$ @$\mathrm{SiO}_{2}$ )-Ag microspheres and $2 \mu \mathrm{l}$ of $\mathrm{C}_{8}-\mathrm{TMS}$ were dispersed in $100 \mathrm{ml}$ of ethanol, stirred them for $10 \mathrm{~h}$ at room temperature. Patchy $\mathrm{C}_{8}-\left(\mathrm{Fe}_{3} \mathrm{O}_{4} @ \mathrm{SiO}_{2}\right)-\mathrm{Ag}$ microspheres were obtained. Thirdly, $10 \mathrm{mg}$ of patchy $\mathrm{C}_{8}-\left(\mathrm{Fe}_{3} \mathrm{O}_{4} @ \mathrm{SiO}_{2}\right)-\mathrm{Ag}$ microspheres were dispersed in $10 \mathrm{ml}$ of $\mathrm{HNO}_{3}(2 \mathrm{M})$ solution and stirred for $100 \mathrm{~min}$ at room temperature. Ag nanoparticles (NPs) were completely dissolved and got patchy $\mathrm{C}_{8}-\left(\mathrm{Fe}_{3} \mathrm{O}_{4} @ \mathrm{SiO}_{2}\right)$ microspheres. Sequentially, $10 \mathrm{mg}$ of patchy $\mathrm{C}_{8}-\left(\mathrm{Fe}_{3} \mathrm{O}_{4} @ \mathrm{SiO}_{2}\right)$ microspheres were dispersed in $100 \mathrm{ml}$ of ethanol, $2 \mu \mathrm{l}$ of $\mathrm{PhCH}_{2} \mathrm{Cl}$-TMS was added and stirred for $10 \mathrm{~h}$ at room temperature. Patchy $\mathrm{C}_{8}-\left(\mathrm{Fe}_{3} \mathrm{O}_{4} @ \mathrm{SiO}_{2}\right)-\mathrm{PhCH}_{2} \mathrm{Cl}$ microspheres were obtained. Finally, $10 \mathrm{mg}$ of patchy $\mathrm{C}_{8}-\left(\mathrm{Fe}_{3} \mathrm{O}_{4} @ \mathrm{SiO}_{2}\right)-$ $\mathrm{PhCH}_{2} \mathrm{Cl}$ microspheres, $1 \mathrm{mg}$ of $\mathrm{NaHCO}_{3}$ and $1 \mathrm{mg}$ of KI were added into $60 \mathrm{ml}$ of DMSO and stirred for $10 \mathrm{~h}$ at $90{ }^{\circ} \mathrm{C}$. Patchy $\mathrm{C}_{8}-\left(\mathrm{Fe}_{3} \mathrm{O}_{4} @ \mathrm{SiO}_{2}\right)-\mathrm{PhCHO}$ microspheres were obtained.

Preparation of single molecular scale thickness Janus nanodiscs. $10 \mathrm{mg}$ of patchy $\mathrm{C}_{8}-\left(\mathrm{Fe}_{3} \mathrm{O}_{4} @ \mathrm{SiO}_{2}\right)-\mathrm{PhCHO}$ microspheres were dispersed in $100 \mathrm{ml}$ of toluene, and $2 \mu \mathrm{l}$ of APTMS was added and stirred for $6 \mathrm{~h}$ at room temperature. The product (S1) was washed by ethanol and dried in vacuum oven. Subsequently, $100 \mathrm{mg}$ of $\mathrm{S} 1$ was added into the mixture containing $95 \mathrm{ml}$ of ethanol and $5 \mathrm{ml}$ of water and stirred them for $10 \mathrm{~h}$ at room temperature. Patchy $\mathrm{C}_{8}-\left(\mathrm{Fe}_{3} \mathrm{O}_{4} @ \mathrm{SiO}_{2}\right)-\mathrm{SiO}_{2}$ microspheres were obtained. Following, dispersed $10 \mathrm{mg}$ of patchy $\mathrm{C}_{8}-\left(\mathrm{Fe}_{3}-\right.$ $\left.\mathrm{O}_{4} @ \mathrm{SiO}_{2}\right)-\mathrm{SiO}_{2}$ microspheres in the solution of $20 \mathrm{ml}$ of ethanol and $20 \mu \mathrm{l}$ of $\mathrm{HCl}(0.1 \mathrm{M})$ under ultrasonic for $2 \mathrm{~min}$, single molecular scale thickness Janus nanodiscs were released from the patchy templated microspheres. The as-formed nanodiscs and magnetic templated microspheres were separated by magnet.

Preparation of functionalized Janus nanodiscs. Firstly, $100 \mathrm{mg}$ of patchy $\mathrm{C}_{8}-\left(\mathrm{Fe}_{3} \mathrm{O}_{4} @ \mathrm{SiO}_{2}\right)-\mathrm{SiO}_{2}$ microspheres and 400 $\mu \mathrm{l}$ of ammonium hydroxide ( $25 \mathrm{wt} \%$ ) were dispersed in $100 \mathrm{ml}$ of ethanol under ultrasonic and strongly stirred at $70{ }^{\circ} \mathrm{C}$. The solution containing with $1.2 \mathrm{ml}$ of $0.1 \mathrm{M} \mathrm{FeCl}_{2} \cdot 4 \mathrm{H}_{2} \mathrm{O}, 1 \mathrm{ml}$ of $0.2 \mathrm{M} \mathrm{FeCl}_{3} \cdot 6 \mathrm{H}_{2} \mathrm{O}$ and $50 \mathrm{ml}$ of ethanol was dropped into the above mixture in $20 \mathrm{~min}$. Patchy $\mathrm{C}_{8}-\left(\mathrm{Fe}_{3} \mathrm{O}_{4} @ \mathrm{SiO}_{2}\right)-\mathrm{SiO}_{2}-\mathrm{Fe}_{3} \mathrm{O}_{4}$ NPs microspheres (S2) were obtained. Secondly, $10 \mathrm{mg}$ of $\mathrm{S} 2$ and $2 \mu \mathrm{l}$ of PEO-TMS were dispersed in $100 \mathrm{ml}$ of ethanol and stirred for $10 \mathrm{~h}$ at room temperature. The patchy $\mathrm{C}_{8}-\left(\mathrm{Fe}_{3} \mathrm{O}_{4} @ \mathrm{SiO}_{2}\right)-$ $\mathrm{SiO}_{2}-\mathrm{Fe}_{3} \mathrm{O}_{4}$ NPs-PEO microspheres (S3) were obtained. Thirdly, $\mathrm{S} 3$ was dispersed in the solution of $20 \mathrm{ml}$ of ethanol and $20 \mu \mathrm{l}$ of $\mathrm{HCl}(0.1 \mathrm{M})$ under ultrasonic for $2 \mathrm{~min}$, then $\mathrm{Fe}_{3} \mathrm{O}_{4}$ NPs-PEO modified Janus nanodiscs (S4) were obtained. Fourthly, $100 \mathrm{mg}$ of S4 was dispersed in $100 \mathrm{ml}$ of ethanol, $200 \mu \mathrm{l}$ of benzaldehyde was added and stirred for $6 \mathrm{~h}$ at room temperature. The phenyl $/ \mathrm{Fe}_{3} \mathrm{O}_{4}$ NPs-PEO modified Janus composite nanodiscs (S5) were obtained. Finally, dispersed $100 \mathrm{mg}$ of S5 in $100 \mathrm{ml}$ of water, $1 \mathrm{mg}$ of $\mathrm{NaBH}_{4}$ was added and stirred for $2 \mathrm{~h}$ at room temperature. The benzyl $/ \mathrm{Fe}_{3} \mathrm{O}_{4}$ NPs-PEO composited Janus nanodiscs (S6) were obtained.

Label of functionalized Janus nanodiscs. $100 \mathrm{mg}$ of S6 was dispersed in $100 \mathrm{ml}$ of water. Then, $1 \mathrm{mg}$ of FITC was added and stirred for $6 \mathrm{~h}$ at room temperature. FITC labelled S6 was obtained.

Emulsification with functionalized Janus nanodiscs. (1) $3 \mathrm{mg}$ of S6 was added to the mixture containing $2 \mathrm{ml}$ of water and $500 \mu \mathrm{l}$ of $n$-heptane under ultrasonic for $3 \mathrm{~min}$. The emulsion of $n$-heptane in water was formed. In order to observation, the $n$-heptane was dyed with coumarine-6; (2) $5 \mathrm{mg}$ of labelled S6 was added to the mixture containing $1 \mathrm{~g}$ of paraffin and $8 \mathrm{~g}$ of water, sheered them at $2000 \mathrm{rpm}$ for $10 \mathrm{~min}$ at $70{ }^{\circ} \mathrm{C}$. The emulsion was achieved.

\section{Characterization}

Morphology of the samples were characterized by scanning electron microscopy (Hitachi S-4800 at $15 \mathrm{kV}$ ), which with an energy dispersive X-ray (EDX) analyser and transmission electron microscopy (JEOL1011 at $100 \mathrm{kV}$ ). The samples for SEM observation were ambient dried and vacuum sputtered with Pt. The samples for TEM observation were prepared by spreading very dilute emulsions in ethanol onto carbon-coated copper grids. FTIR spectroscopy was performed on the sample/KBR pressed pellets after scanning samples for 32 times using 
a BRUKER EQUINOX55 spectrometer. Thickness and shape of the samples was measured by AFM of Bruker Multimode 8 . Emulsion was characterized by inverted fluorescence microscopy (Olympus IX83) and Olympus optical microscope. Size contribution was measured by Zeta-sizer (Nano Series, Malvern Instruments) at $25{ }^{\circ} \mathrm{C}$.

\section{Results and discussion}

The $\mathrm{Fe}_{3} \mathrm{O}_{4} @ \mathrm{SiO}_{2}$ microsphere is prepared by solvothermal method following a $\mathrm{SiO}_{2}$ layer coating via sol-gel process. ${ }^{\mathbf{1 0}}$ The representative $\mathrm{Fe}_{3} \mathrm{O}_{4}$ microsphere (200 $\mathrm{nm}$ in diameter) is selected as a paramagnetic core for easy separation (Fig. S1 $\dagger$ ). Onto the $\mathrm{Fe}_{3} \mathrm{O}_{4}$ microsphere surface, $\mathrm{SiO}_{2}$ is detected by EDX (Fig. S2a and $\mathrm{b} \dagger$ ). The size contribution of $\mathrm{Fe}_{3} \mathrm{O}_{4}$ and $\mathrm{Fe}_{3} \mathrm{O}_{4}$ @$\mathrm{SiO}_{2}$ microspheres is measured by DLS, which is consistent with TEM results (Fig. S2c $\dagger$ ). The thickness of $\mathrm{SiO}_{2}$ layer is about 30$40 \mathrm{~nm}$ (Fig. S3a $\dagger$ ). Onto the $\mathrm{Fe}_{3} \mathrm{O}_{4} @ \mathrm{SiO}_{2}$ microsphere, $\mathrm{Ag}$ NPs are achieved by reducing $\mathrm{AgNO}_{3}$ with $n$-butylamine at $50{ }^{\circ} \mathrm{C}$ (Fig. S3b $\dagger$ ). ${ }^{11}$ The diameter of Ag NPs can be adjusted with reaction time. The exposed bare $\mathrm{SiO}_{2}$ surface is treated to be hydrophobic with n-octyltrimethoxysilane ( $\left.\mathrm{C}_{8}-\mathrm{TMS}\right)$. Then, a $\mathrm{C}_{8}-\left(\mathrm{Fe}_{3} \mathrm{O}_{4} @ \mathrm{SiO}_{2}\right)-\mathrm{Ag}$ composite microsphere is achieved (Fig. 1a). Upon removal of Ag NPs by dissolution, surface of the microsphere becomes smooth, and fresh $\mathrm{SiO}_{2}$ domains are exposed (Fig. S3c $\dagger$ ). The fresh $\mathrm{SiO}_{2}$ domains are further modified with 4-(chloromethyl)phenyltrimethoxysilane $\left(\mathrm{PhCH}_{2} \mathrm{Cl}-\right.$ TMS) to graft benzyl chloride groups (Fig. S3d†). Benzaldehyde groups are derived from the benzyl chloride groups by Kornblum oxidation. ${ }^{12}$ A patchy $\mathrm{C}_{8}-\left(\mathrm{Fe}_{3} \mathrm{O}_{4} @ \mathrm{SiO}_{2}\right)-\mathrm{PhCHO}$ microsphere is achieved (Fig. 1b). The surface remains smooth. 3Aminopropyltrimethoxysilane (APTMS) can form a monolayer onto the patchy domains since the aldehyde group can form a dynamic imine bond with the functional amine-group of APTMS. The amine-groups are prevented thereby. The pedant silane groups can form a molecular thick silica layer via sol-gel

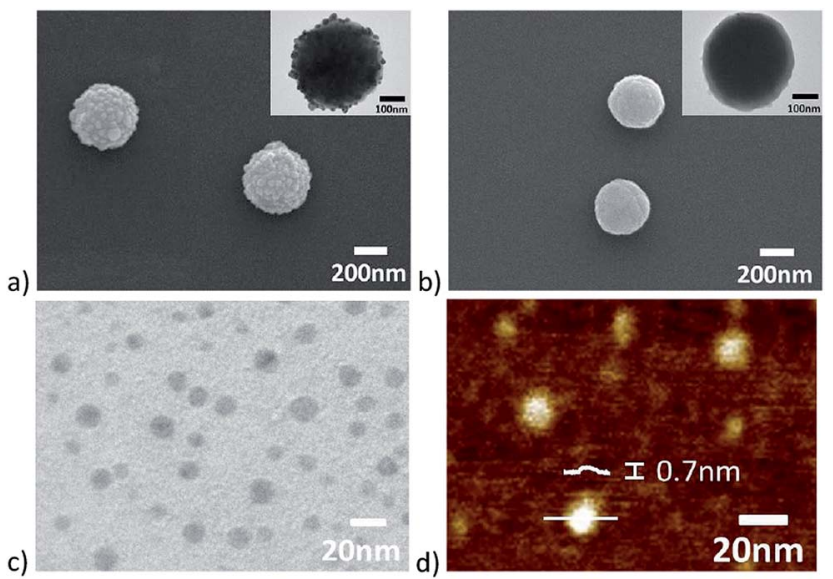

Fig. 1 Morphologies of paramagnetic microspheres and as-formed Janus nanodiscs: SEM and inset TEM images of (a) patchy $\mathrm{C}_{8}-\left(\mathrm{Fe}_{3}-\right.$ $\mathrm{O}_{4}\left(\mathrm{aSiO}_{2}\right)-\mathrm{Ag}$ microspheres; (b) patchy $\mathrm{C}_{8}-\left(\mathrm{Fe}_{3} \mathrm{O}_{4}\left(\mathrm{aSiO}_{2}\right)-\mathrm{PhCHO}\right.$ microspheres; TEM (c) and AFM (d) images of the as-formed Janus nanodiscs. process. The sphere surface remains smooth (Fig. S3e and $f \dagger$ ). After adding acid, the imine bond is broken. Then, the silica nanodiscs are released from the microsphere. Using a magnet, the patchy template microspheres are recycled, while the nanodiscs are purified.

The compositions of different microspheres are measured by FTIR spectrum (Fig. S4 $\dagger$ ). Characteristic peaks at $2840 \mathrm{~cm}^{-1}$ and $2920 \mathrm{~cm}^{-1}$ are respectively assigned to $-\mathrm{CH}_{3}$ group and $-\mathrm{CH}_{2}-$ group, which prove that the patchy $\mathrm{C}_{8}-\left(\mathrm{Fe}_{3} \mathrm{O}_{4} @ \mathrm{SiO}_{2}\right)$ microspheres are prepared. Characteristic peaks at $1600-1400 \mathrm{~cm}^{-1}$ are assigned to phenyl group, which proves that the patchy $\mathrm{C}_{8}-$ $\left(\mathrm{Fe}_{3} \mathrm{O}_{4} @ \mathrm{SiO}_{2}\right)-\mathrm{PhCH}_{2} \mathrm{Cl}$ microspheres had been prepared. Meanwhile, the characteristic peak at $1750 \mathrm{~cm}^{-1}$ is assigned to -CHO group, it is shown that the patchy $\mathrm{C}_{8}-\left(\mathrm{Fe}_{3} \mathrm{O}_{4} @ \mathrm{SiO}_{2}\right)-$ PhCHO microspheres are achieved. The peaks at $3404 \mathrm{~cm}^{-1}$ and $3520 \mathrm{~cm}^{-1}$ are assigned to $-\mathrm{NH}_{2}$ group of APTMS which is grafted onto the - $\mathrm{PhCHO}$ group region of patchy $\mathrm{C}_{8}-\left(\mathrm{Fe}_{3} \mathrm{O}_{4}\right.$ @a$\mathrm{SiO}_{2}$ )-PhCHO microspheres.

When $\mathrm{pH}$ is tuned to about 4.5, aminopropyl/hydroxyl composited Janus nanodiscs are released from the templated microspheres for the dynamic imine bond is cleaved. The average size of Janus nanodiscs is about $15 \mathrm{~nm}$ in diameter (Fig. 1c). The thickness of Janus nanodiscs is about $0.7 \mathrm{~nm}$ (Fig. 1d). Shape and size of the aminopropyl/hydroxyl composited Janus nanodiscs are uniform. Because of the as-formed Janus nanodiscs are too thin to observe in SEM, they can only be characterized by TEM and AFM in morphology. The compositions of the as-formed Janus nanodiscs are measured by FTIR spectrum (Fig. S5 $\dagger$ ). The peaks at $3448 \mathrm{~cm}^{-1}$ and 3360 $\mathrm{cm}^{-1}$ are assigned to $-\mathrm{NH}_{2}$ group, the peaks $3155 \mathrm{~cm}^{-1}$ are assigned to $-\mathrm{OH}$ group, and the peak at $1090 \mathrm{~cm}^{-1}$ are assigned to $-\mathrm{Si}-\mathrm{O}-\mathrm{Si}-$ bond.

The single molecular scale thickness Janus nanodiscs are prepared from the domains where the Ag NPs are. So the size of Janus nanodiscs can be adjusted by controlling the size of $\mathrm{Ag}$ NPs. It is found that the Ag NPs grow bigger with the increase of reaction time. When the reaction time is $40 \mathrm{~min}$, the diameters of Ag NPs are about $5 \mathrm{~nm}$ (Fig. S6a $\dagger$ ). Then the as-formed Janus nanodiscs are about $5 \mathrm{~nm}$ in diameter (Fig. 2a). When the reaction time is increased to $60 \mathrm{~min}$, the average diameters of both Ag NPs and as-formed Janus nanodiscs are about $25 \mathrm{~nm}$ (Fig. S6b, $\uparrow$ and $2 \mathrm{~b}$ ). Thus, the size of the single molecular thickness Janus nanodiscs can be precisely controlled. However, the thickness of the Janus nanodiscs with different sizes remains $0.7 \mathrm{~nm}$ (Fig. 2c and d).

Two sides of the as-formed Janus nanodiscs are easily to be selectively modified with different compositions, respectively. Firstly, $\mathrm{Fe}_{3} \mathrm{O}_{4}$ NPs are grafted onto the hydroxyl group side by coprecipitation method. ${ }^{13} \mathrm{Fe}_{3} \mathrm{O}_{4}$ NPs are barely recognized on the surface of patchy $\mathrm{C}_{8}-\left(\mathrm{Fe}_{3} \mathrm{O}_{4} @ \mathrm{SiO}_{2}\right)-\mathrm{SiO}_{2}$ microsphere (Fig. 3a). When $\mathrm{pH}$ is tuned to about 4.5 , aminopropyl $/ \mathrm{Fe}_{3} \mathrm{O}_{4}$ NPs composited Janus nanodiscs are released from the templated microspheres (Fig. 3b). It is easy to find the $\mathrm{Fe}_{3} \mathrm{O}_{4} \mathrm{NPs}$ exist on the surface of the Janus composite nanodiscs. In order to enhancing hydrophilic property of the Janus composite nanodiscs, 2-[methoxy(polyethyleneoxy) ${ }_{6-9}$ propyl]trimethoxysilane (PEO-TMS) are grafted on the $\mathrm{Fe}_{3} \mathrm{O}_{4}$ NPs side via sol-gel 
a)

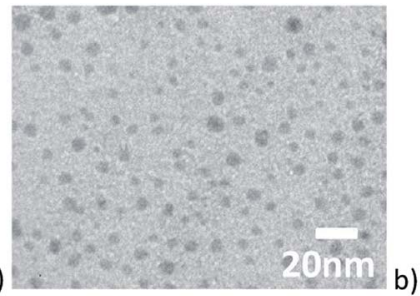

c)
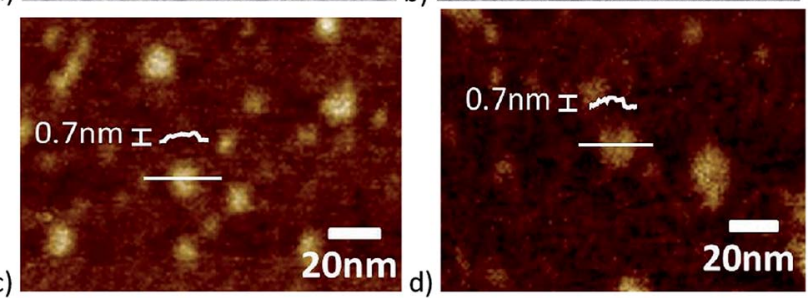

Fig. 2 Size control of the as-formed Janus nanodiscs. TEM and AFM images of the aminopropyl/hydroxyl composited Janus nanodiscs are achieved at different reaction time: (a) and (c) are at $40 \mathrm{~min}$; (b) and (d) are at $60 \mathrm{~min}$

a)
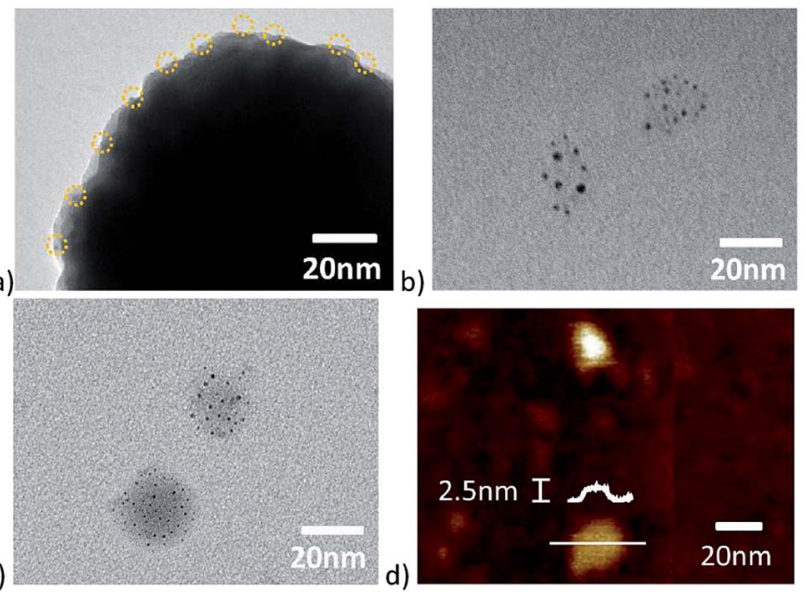

Fig. 3 Morphologies of different Janus nanodiscs: (a) TEM image of patchy $\mathrm{C}_{8}-\left(\mathrm{Fe}_{3} \mathrm{O}_{4}\left(\mathrm{aSiO}_{2}\right)-\mathrm{SiO}_{2}-\mathrm{Fe}_{3} \mathrm{O}_{4} \mathrm{NPs}\right.$ microsphere; (b) TEM image of $\mathrm{Fe}_{3} \mathrm{O}_{4} \mathrm{NPs}$ modified Janus nanodiscs; TEM (c) and AFM (d) images of benzyl/ $/ \mathrm{Fe}_{3} \mathrm{O}_{4} \mathrm{NPs}-\mathrm{PEO}$ Janus composite nanodiscs.

reaction. The patchy $\mathrm{C}_{8}-\left(\mathrm{Fe}_{3} \mathrm{O}_{4} @ \mathrm{SiO}_{2}\right)-\mathrm{SiO}_{2}-\mathrm{Fe}_{3} \mathrm{O}_{4}$ NPs-PEO microspheres are achieved (Fig. S7 $\dagger$ ). Turn pH to about 4.5, the $\mathrm{Fe}_{3} \mathrm{O}_{4}$ NPs-PEO modified Janus composite nanodiscs are achieved from the templated microspheres. Then, benzaldehyde is grafted to the aminopropyl group via Schiff base reaction, and further imine bonds are reduce with $\mathrm{NaBH}_{4}$. So the benzyl/ $\mathrm{Fe}_{3} \mathrm{O}_{4}$ NPs-PEO Janus nanodiscs are fabricated (Fig. 3c). Hydrophilic PEO group and hydrophobic benzyl group are respectively grafted onto the two sides of the as-formed Janus nanodiscs. For the existence of $\mathrm{Fe}_{3} \mathrm{O}_{4}$ NPs, PEO and benzyl groups, thickness of the Janus nanodiscs increase to about $2.5 \mathrm{~nm}$ (Fig. 3d). But the size of Janus nanodiscs does not change obviously. The compositions of different Janus nanodiscs are proved by FTIR spectrum (Fig. S8 $\dagger$ ). The character peak at $506 \mathrm{~cm}^{-1}$ indicates $\mathrm{Fe}-\mathrm{O}$ bond, and peak at $1090 \mathrm{~cm}^{-1}$ indicates -Si-O-Si- bond. Meanwhile, the peaks at $1390 \mathrm{~cm}^{-1}$ and $1690 \mathrm{~cm}^{-1}$ respectively indicate $\mathrm{C}-\mathrm{N}$ and $\mathrm{C}=\mathrm{N}$ bonds.
In order to prove their amphiphilic property which originated from their Janus structures, aggregation structures of Janus nanodiscs in different solvents are studied. When the Janus nanodiscs are dispersed in selective solvent such as water, the hydrophobic benzyl side is stacked together while the hydrophilic PEO side exposes to the aqueous phase to form back-to-back stacked aggregates for their amphiphilic property originated from their Janus structure (Fig. S9a†). Similarly in cyclohexane, the hydrophilic PEO side is stacked together while the hydrophobic benzyl side exposes to the cyclohexane phase to form large size aggregates (Fig. S9b $\dagger$ ). When the Janus nanodiscs are dispersed in co-solvent THF, Janus nanodiscs are mono-dispersed as single particles (Fig. S9c†). Meanwhile, DLS data shown that Janus nanodiscs aggregate together to form large size aggregated particles in selective solvents and are dispersed as single particles in co-solvent, respectively (Fig. S9d广).

For the magnetic responsive property of $\mathrm{Fe}_{3} \mathrm{O}_{4}$ NPs, the asprepared Janus nanodiscs can be easily manipulated with external magnetic field (Fig. S9†). The as-prepared Janus nanodiscs can be employed as solid surfactants to stabilize emulsion. Taking water and $n$-heptane as immiscible solvents, they are emulsified to oil-in-water emulsion (Fig. 4a). For their magnetic property, Janus composite nanodiscs can be collected with magnet and reused. In order to observe the as-stabilized emulsion droplets more clearly, melt paraffin $\left(T_{\mathrm{m}}=52-54{ }^{\circ} \mathrm{C}\right)$ is used as oil phase. Then a paraffin-in-water emulsion forms upon $70^{\circ} \mathrm{C}$ and stirring at $2000 \mathrm{rpm}$ for $10 \mathrm{~min}$. The paraffin-inwater emulsion could be stable for several months and the diameter of paraffin droplets is $2-5 \mu \mathrm{m}$ (Fig. $4 \mathrm{~b}$ ). After the emulsion is cooled down to room temperature, the paraffin is solidified (Fig. 4c). FITC is employed to observe the positions of as-used Janus nanodiscs in emulsion system. It is shown that all

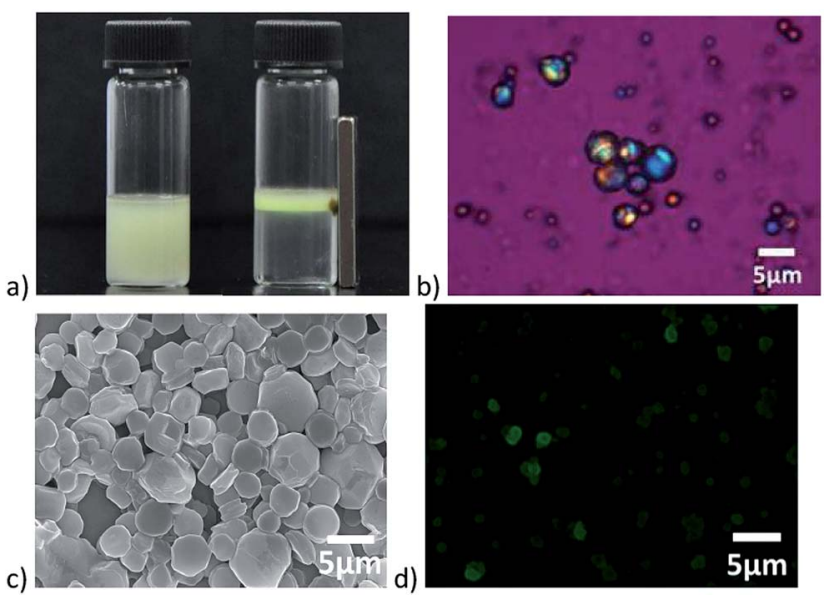

Fig. 4 Performance demonstration of the as-prepared Janus nanodiscs: (a) magnetic performance: the as-prepared Janus nanodiscs are served as solid surfactant in the $n$-heptane-in-water emulsion, the $n$ heptane is dyed by coumarine- 6 (left), and the as-used Janus nanodiscs are easily collected by magnet (right); (b) polarizing optical image of the paraffin-in-water emulsion; (c) SEM image of the paraffin droplets; (d) inverted fluorescence microscope image of the paraffinin-water emulsion. 
the Janus nanodiscs aggregate at the interface of emulsion (Fig. 4d). So the as-prepared Janus nanodiscs are a kind of efficient solid emulsion stabilizer.

\section{Conclusions}

In summary, single molecular scale thickness Janus nanodiscs are successfully achieved from patchy $\mathrm{C}_{8}-\left(\mathrm{Fe}_{3} \mathrm{O}_{4} @ \mathrm{SiO}_{2}\right)-$ PhCHO microspheres as template. The sizes of Janus nanodiscs can be controlled by tuning the patchy domains. Meanwhile, paramagnetic $\mathrm{Fe}_{3} \mathrm{O}_{4}$ NPs are introduced onto the hydrophilic side of the Janus nanodiscs thus achieving magnetic response. Further, benzyl groups and PEO groups are grafted respectively onto the hydrophobic and hydrophilic sides of the as-formed Janus nanodiscs to enhance their amphiphilic performance. The as-prepared Janus composite nanodiscs can be used as recyclable solid surfactants to stabilize emulsion. Most importantly, the patchy $\mathrm{C}_{8}-\left(\mathrm{Fe}_{3} \mathrm{O}_{4} @ \mathrm{SiO}_{2}\right)-\mathrm{PhCHO}$ templated microspheres can be easily recovered and reused to fabricate more Janus nanodiscs.

\section{Acknowledgements}

This work was supported by the National Natural Science Foundation of China $(51233007,51622308)$.

\section{Notes and references}

1 S. Jiang and S. Granick, Janus particle synthesis, self-assembly and applications, RSC Press, London, England, 2012;
A. Walther and A. H. E. Müller, Chem. Rev., 2013, 113, 5194; F. X. Liang, C. L. Zhang and Z. Z. Yang, Adv. Mater., 2014, 26, 6944.

2 A. Walther, K. Matussek and A. H. E. Müller, ACS Nano, 2008, 2, 1167; A. Walther, M. Drechsler and A. H. E. Müller, Soft Matter, 2009, 5, 385; A. Walther, M. Hoffmann and A. H. E. Müller, Angew. Chem., Int. Ed., 2008, 120, 711.

3 A. C. Trindade, R. Craveiro, A. P. C. Almeida, J. P. Canejo, A. Paiva, S. Barreiros and M. H. Godinho, J. Supercrit. Fluids, 2017, 120, 125.

4 B. Zhao, H. Zhou, C. Y. Liu, Y. Long, G. Q. Yang, C. H. Tung and K. Song, New J. Chem., 2016, 40, 6541.

5 F. X. Liang, K. Shen, X. Z. Qu, C. L. Zhang, Q. Wang, J. L. Li, J. G. Liu and Z. Z. Yang, Angew. Chem., Int. Ed., 2011, 50, 2379.

6 F. X. Liang, J. G. Liu, C. L. Zhang, X. Z. Qu, J. L. Li and Z. Z. Yang, Chem. Commun., 2011, 47, 1231.

7 Y. Nonomura, S. Komura and K. Tsujii, Langmuir, 2004, 20, 11821.

8 A. Walther, X. Andre, M. Drechsler, V. Abetz and A. H. E. Müller, J. Am. Chem. Soc., 2007, 129, 6187.

9 Y. J. Liu, F. X. Liang, Q. Wang, X. Z. Qu and Z. Z. Yang, Chem. Commun., 2015, 51, 3562; Y. J. Liu, Q. Wang, X. Z. Qu, F. X. Liang and Z. Z. Yang, Sci. China Mater., 2015, 58, 126.

10 Y. H. Deng, D. W. Qi, C. H. Deng, X. M. Zhang and D. Y. Zhao, J. Am. Chem. Soc., 2008, 130, 28.

11 K. Kim, H. S. Kim and H. K. Park, Langmuir, 2006, 22, 8083. 12 W. W. Epstein and F. W. Sweat, Chem. Rev., 1967, 67, 247. 13 R. Massart, IEEE Trans. Magn., 1981, 17, 1247. 